Research Paper

\title{
The overexpression of MDM4: an effective and novel predictor of gastric adenocarcinoma lymph node metastasis
}

\author{
Junjie Bao ${ }^{1,2, *}$, Abiyasi Nanding ${ }^{3, *}$, Haibin Song ${ }^{1, *}$, Rui Xu' ${ }^{4, *}$, Guofan Qu ${ }^{2}$, Yingwei \\ $\mathrm{Xue}^{1}$ \\ ${ }^{1}$ Department of Gastroenterologic Surgery, Harbin Medical University Cancer Hospital, Harbin, China \\ ${ }^{2}$ Department of Orthopedics, Harbin Medical University Cancer Hospital, Harbin, China \\ ${ }^{3}$ Department of Pathology, Harbin Medical University Cancer Hospital, Harbin, China \\ ${ }^{4}$ Department of Dermatology, Harbin Children's hospital, Harbin, China \\ *These authors contributed equally to this work \\ Correspondence to: Yingwei Xue, email: xyw801@163.com \\ Guofan Qu, email: 67220591@qq.com
}

Keywords: MDM4, gastric adenocarcinoma, clinicopathological parameters, lymph node metastasis

Received: May 07, 2016

Accepted: September 02, 2016

Published: September 12, 2016

\section{ABSTRACT}

Background: MDM4 is the important negative regulator of the tumor suppressor protein p53, which is overexpressed in various human cancers. This study evaluates the MDM4 expression in patients with gastric adenocarcinoma (GTAC) at the mRNA and protein levels and examines relationships among MDM4 expression, clinicopathological features, and prognosis.

Results: The qRT-PCR and the Western blot analysis showed that the MDM4 expression level was high in $\mathrm{GTACN}^{+}$but not in $\mathrm{GTACN}^{-}$. The high expression level of MDM4 was significantly associated with age $(P=0.047)$, lymph node metastasis (LNM) $(P<0.001)$, pathological stage $(P<0.001)$, differentiation status $(P=0.001)$, and preoperative serum CA19-9 level $(P<0.001)$. Moreover, the survival analysis showed that Borrmann type, depth of invasion, LNM, and preoperative serum CA199 level were independent prognostic factors. The univariate analysis revealed that MDM4 expression influenced GTAC prognosis. Furthermore, the influence of overall prognosis relies on whether or not the high MDM4 expression level could lead to LNM.

Materials and Methods: We investigated MDM4 expression in primary GTAC and paired normal gastric tissues (30 pairs) through qRT-PCR and Western blot analyses. We also performed immunohistochemistry analysis on 336 paraffin-embedded GTAC specimens and 33 matched normal specimens.

Conclusions: MDM4 expression may result in LMN of GTAC. High MDM4 expression levels are associated with LMN of GTAC and influence the prognosis of patients with GTAC.

\section{INTRODUCTION}

Gastric cancer, a common malignant tumor, remains a major cause of death worldwide despite its decreased incidence over past decades [1,2]. About $90 \%$ to $95 \%$ of Gastric cancers are adenocarcinomas. Lymph node metastasis (LNM) is an important prognostic factor in gastric cancer [3, 4]. Among patients with R0 resection for gastric cancer, LN status is the most important independent prognostic factor, followed by $\mathrm{pT}$ category, surgical complication, and distant metastasis [5]. No accurate and reliable judgment of preoperative LNM has been established for patients with GTAC. Enhanced computed tomography (CT) is routinely used to evaluate LNM in gastric cancer, with a sensitivity of $80.0 \%$ and a specificity of $77.8 \%$ based on the size of LN [6]. However, the sensitivity of CT imaging is only $6.1 \%$, and metastasized lymph nodes are smaller than $5 \mathrm{~mm}$ [7]. Accurate 
knowledge of the LN status helps predict prognosis and plan the extent of lymphadenectomy. Therefore, objective markers must be developed to identify LNM in GC.

The MDM4 gene encodes a nuclear protein that contains a p53-binding domain at the N-terminus and a RING finger domain at the C-terminus. MDM4 is overexpressed in various human cancers [8, 9]. MDM4 inhibits p53 by binding to its transcriptional activation domain. In addition, MDM4 interacts with the MDM2 protein via the RING finger domain and inhibits the degradation of the latter [10]. We collected microarray data of 186 GTAC cases and 33 normal gastric tissue cases from the Cancer Genome Atlas database. The bioinformatic screening showed that MDM4 expression is associated with LNM of GTAC $\left(\mathrm{GTACN}^{+}\right)$. Similar approaches have been widely applied in previous studies $[11,12]$. The screening results need to be examined by further investigations. Therefore, the purpose of this study is to verify the relationship between MDM4 and LNM in GTAC.

\section{RESULTS}

\section{Overexpression of MDM4 in fresh GTACN ${ }^{+}$ tissues}

The result of the bioinformatics analysis was verified by the first analyzing MDM4 expression in 30 pairs of GTAC and matched adjacent normal tissues at the mRNA level. 18 patients with GTAC exhibited positive LNM $\left(\mathrm{GTACN}^{+}\right)$. qRT-PCR results showed that 14/18 $\mathrm{GTACN}^{+}$displayed high MDM4 expression level (Figure 1A), which differed between the two groups $(t=2.695, P=0.015) .12$ patients with GTAC showed negative LNM (GTACN ${ }^{-}$). 7/12 $\mathrm{GTACN}^{+}$displayed high MDM4 expression level (Figure 1B), which differed between the two groups $(t=0.355, P=0.729)$.

The Western blot analysis was employed to determine the expression status in 30 pairs of fresh GTAC and adjacent normal gastric tissues and protein expression of MDM4 in GTAC. The results showed that MDM4 expression is high in $\mathrm{GTACN}^{+}(10 / 18)$ (Figure 2A) but low in GTACN $^{-}(5 / 12)$ (Figure 2B). The result of the Western blot analysis was conformed with that of qRTPCR in the 30 pairs of fresh GTAC tissues.

\section{Overexpression of MDM4 is associated with the clinicopathological characteristics of patients with GTAC}

Overall, 36.6\% (123/336) of tumor sections and $15.2 \%(5 / 33)$ of the corresponding adjacent normal gastric tissue sections $(P=0.009)$ were classified as the MDM4 high expression. (Figure 3A-3D).

Statistical analyses were performed to investigate possible correlations between MDM4 expression and clinicopathological characteristics of patients. The analysis of 336 GTAC cases indicated that MDM4 expression was associated with age $(P=0.047)$, LNM $(P<0.001)$, pathological stage $(P<0.001)$, differentiation status $(P=0.001)$, and preoperative serum CA19-9 $(P<0.001)$ (Table 1$)$.

\section{Univariate and multivariate analyses of the predictor of clinical outcomes in GTAC}

The univariate analysis showed a significant relationship between overall survival and tumor size [hazard ratio $(\mathrm{HR})=2.269 ; 95 \%$ confidence interval $(95 \% \mathrm{CI})=1.661-3.100 ; P<0.001)]$, Borrmann type $(\mathrm{HR}=2.810 ; 95 \% \mathrm{CI}=1.870-4.223 ; P<0.001)$, depth of invasion $(\mathrm{HR}=5.507 ; 95 \% \mathrm{CI}=3.329-9.108 ; P<0.001)$, LNM $(\mathrm{HR}=4.407 ; 95 \% \mathrm{CI}=2.990-6.494 ; P<0.001)$, pathological stage $(\mathrm{HR}=3.567 ; 95 \% \mathrm{CI}=2.593-4.906$; $P<0.001)$, differentiation status $(\mathrm{HR}=1.829 ; 95 \% \mathrm{CI}$ $=1.224-2.732 ; P<0.001)$, preoperative serum CA19$9(\mathrm{HR}=2.691 ; 95 \% \mathrm{CI}=1.856-3.902 ; P<0.001)$, and high MDM4 expression $(\mathrm{HR}=1.943 ; 95 \% \mathrm{CI}=$ $1.430-2.6413 ; P<0.001)$. The multivariate analysis used the four significant parameters identified Borrmann type $(\mathrm{HR}=1.719 ; 95 \% \mathrm{CI}=1.119-2.640 ; P=0.013)$, depth of invasion $(\mathrm{HR}=2.810 ; 95 \% \mathrm{CI}=1.551-5.092 ; P=0.001)$, LNM $(\mathrm{HR}=3.256 ; 95 \% \mathrm{CI}=1.913-5.541 ; P<0.001)$, and preoperative serum CA19-9 $(\mathrm{HR}=1.796 ; 95 \% \mathrm{CI}=1.208$ 2.671; $P=0.004$ ) (Table 2).

The Kaplan-Meier analysis and log-rank test showed that patients with Borrmann types III-IV had a significantly shorter overall survival than those with Borrmann types 0 -II $(P=0.013$; Figure 4A). Patients with T3-4 had a significantly shorter overall survival than those with T1-2 $\left(P=0.001\right.$; Figure 4B). Patients with $\mathrm{N}^{+}$had significantly shorter overall survival than those with $\mathrm{N}^{-}(P<0.001$; Figure 4C). Patients with high preoperative serum CA19-9 had significantly shorter overall survival than those with normal preoperative serum CA19-9 ( $P=0.004$; Figure 4D).

\section{DISCUSSION}

LNM is one of the most important prognostic factors in patients with gastric cancer $[5,13]$. The LNM status is the most important prognostic factor in patients with resectable gastric cancer, followed by p T staging, surgical complications, and distant metastasis [5]. Therefore, LNM status must be accurately assessed to predict the prognosis of patients and draft surgical plans. The 3D CT scan is commonly used in the clinical evaluation of patients with gastric cancer with LNM status based on the size of lymph nodes [6]. However, lymph node size is not a reliable indicator for LNM in patients with gastric cancer [14]. Preoperative accurate prediction of LNM status has special clinical significance for gastric cancer. To the best 
Table 1: Correlation among MDM4 expression and the clinicopathological features of patients with GTAC

\begin{tabular}{|c|c|c|c|}
\hline Variables & MDM4 (high) (123) & MDM4 (low) (213) & $P$ \\
\hline Age (years) & & & 0.047 \\
\hline$<58$ & $71(57.7 \%)$ & $99(46.6 \%)$ & \\
\hline$\geq 58$ & $52(42.3 \%)$ & $114(53.6 \%)$ & \\
\hline Gender & & & 0.437 \\
\hline Male & $84(68.3 \%)$ & $154(72.3 \%)$ & \\
\hline Female & $39(31.7 \%)$ & $59(27.7 \%)$ & \\
\hline Tumour size (cm) & & & 0.301 \\
\hline$>5$ & $51(41.5 \%)$ & $103(48.4 \%)$ & \\
\hline$\leq 5$ & $72(58.5 \%)$ & $109(51.6 \%)$ & \\
\hline Borrmann type & & & 0.402 \\
\hline $0-\mathrm{II}$ & $35(28.5 \%)$ & $70(32.9 \%)$ & \\
\hline III-IV & $88(71.5 \%)$ & $143(67.1 \%)$ & \\
\hline Depth of invasion & & & 0.286 \\
\hline $\mathrm{T} 1-2$ & $33(26.8 \%)$ & $69(32.4 \%)$ & \\
\hline T3-4 & $90(73.2 \%)$ & $144(67.6 \%)$ & \\
\hline Lymph node metastasis & & & 0.000 \\
\hline $\mathrm{N}^{-}$ & $18(14.6 \%)$ & $121(56.8 \%)$ & \\
\hline $\mathrm{N}^{+}$ & $105(85.4 \%)$ & $92(43.2 \%)$ & \\
\hline Pathological Stage & & & 0.000 \\
\hline I & $12(9.8 \%)$ & $57(26.8 \%)$ & \\
\hline II & $37(30.1 \%)$ & $86(40.4 \%)$ & \\
\hline III & $74(60.2 \%)$ & $70(32.8 \%)$ & \\
\hline Differentiation status & & & 0.005 \\
\hline Differentiation & $20(16.3 \%)$ & $64(30.0 \%)$ & \\
\hline Lack of differentiation & $103(83.7 \%)$ & $149(70.0 \%)$ & \\
\hline Preoperative serum CEA & & & 0.195 \\
\hline High & $22(17.9 \%)$ & $51(23.9 \%)$ & \\
\hline Normal & $101(82.1 \%)$ & $162(76.1 \%)$ & \\
\hline Preoperative serum CA19-9 & & & 0.000 \\
\hline High & $29(23.6 \%)$ & $18(8.5 \%)$ & \\
\hline Normal & $94(76.4 \%)$ & $195(91.5 \%)$ & \\
\hline
\end{tabular}

of our knowledge, this study is the first to demonstrate the correlation between LNM and the MDM4 expression in GTAC.

In this study, we investigated MDM4 expression status in GTAC at both mRNA and protein levels. MDM4 was significantly overexpressed in $\mathrm{GTACN}^{+}$. Furthermore, a high MDM4 expression level was significantly associated with age, lymph node metastatic status, pathological stage, differentiation status, and preoperative serum CA19-9. Gastric cancer in young adults was more likely associated with LNM $[15,16]$. Lack of differentiation $[17,18]$ and high preoperative serum CA19-9 $[19,20]$ were associated with LNM in gastric cancer. High MDM4 expression level was significantly associated with age, LNM, pathological stage, differentiation status, and preoperative serum CA19-9. Our result was consistent with the previous research, which showed that high MDM4 expression was associated with LNM of GTAC. Ach et al. [21] showed that MDM4 aberrations were correlated with LNM of salivary gland cancer.

Borrmann type, depth of invasion, LNM $(P<0.001)$, and preoperative CA19-9 level $(P=0.009)$ were also independent factors influencing the prognosis of GTAC. Patients with Borrmann types III/IV often have a poor prognosis [22]. Particularly, lymph node and distant 
metastases are common in patients with Borrmann type IV [22-24]. Luo et al. [23] performed a meta-analysis of patients with gastric cancer of type IV Borrmann and poor tumor differentiation; the results indicated that these patients were prone to LNM, distant metastasis, serosal invasion, and lymph node invasion and had a poor prognosis. Our results showed that Borrmann type was an independent factor influencing GTAC prognosis. This result was consistent with that obtained by other researchers. Previous studies demonstrated that the depth of invasion was an independent prognostic indicator of GTAC $[25,26]$. This study indicated that patients with T3-4 had significantly shorter overall survival than those with T1-2. The survival analysis showed that the depth of invasion was an independent prognostic indicator for GTAC. Such a finding was consistent with the previous research. LNM is the most important factor for the prognosis of patients with gastric cancer $[27,28]$. In this study, high MDM4 expression was associated with LNM of GTAC. The univariate analysis showed that MDM4 expression influences the prognosis of GTAC. However, the multivariate analysis showed that the MDM4 expression was not an independent prognostic factor of GTAC. Accordingly, the influence of MDM4 on GTAC prognosis depended on whether it could lead to LNM of GTAC [28]. Increased CA19-9 level indicates poor GC prognosis [29, 30]. Yajima et al. [29] reported that CA19-9-producing gastric cancer had poor prognosis characterized by high preoperative serum CA19-9. Our findings showed that high preoperative serum CA19-9 was an independent prognostic factor for GTAC.

In conclusion, we showed that high MDM4 expression was associated with LNM of GTAC. The univariate analysis showed that MDM4 expression influenced the prognosis of GTAC, and the influence
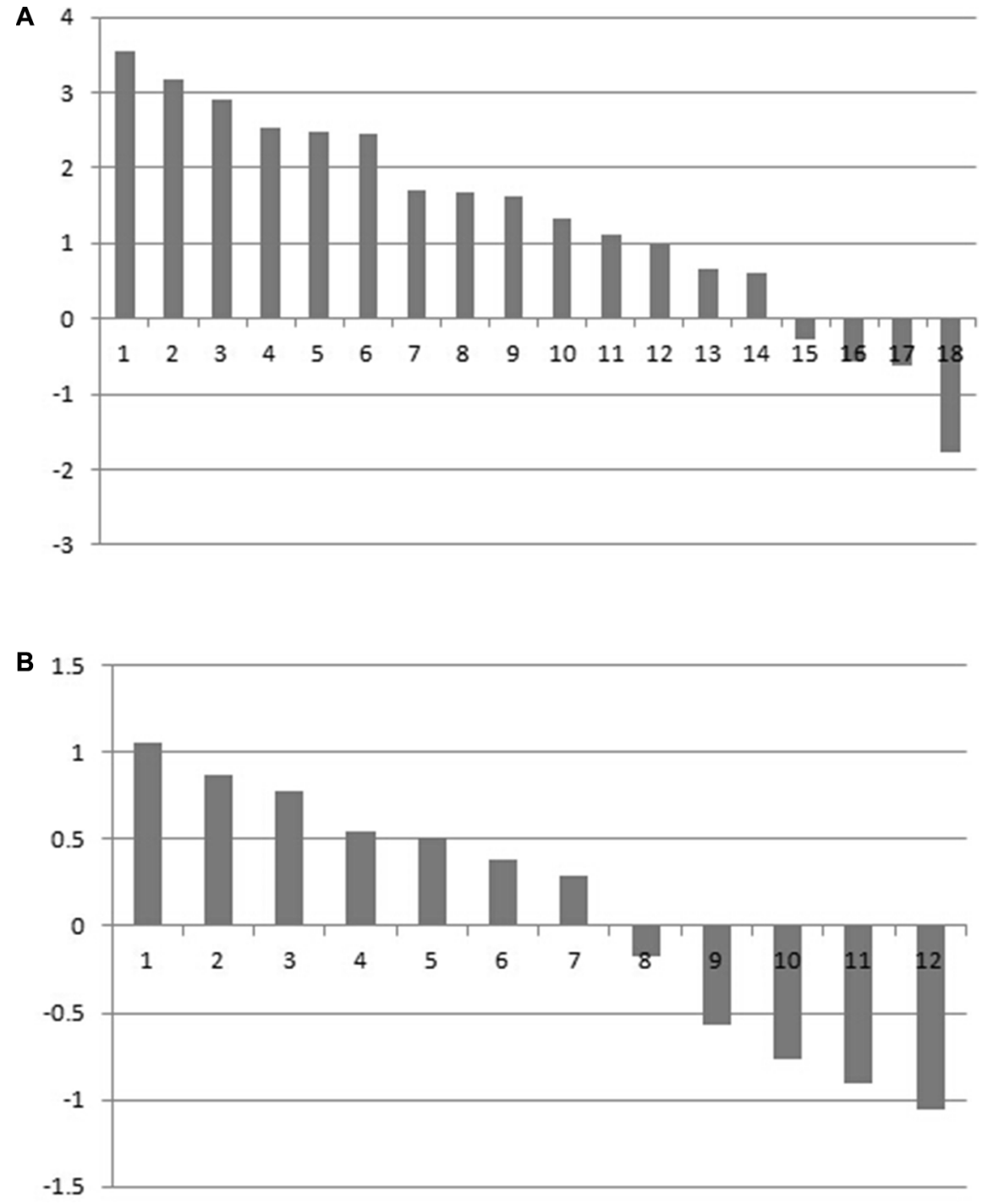

Figure 1: (A) MDM4 mRNA expression in GTAC tissues with positive lymph node metastasis and corresponding normal tissues. (B) MDM4 mRNA expression in GTAC tissues with negative lymph node metastasis and corresponding normal tissues. 
A

$\begin{array}{llllll}\mathrm{C}^{\mathrm{N}} & \mathrm{N} & \mathrm{C}^{\mathrm{N}+} & \mathrm{N} & \mathrm{C}^{\mathrm{N}+} & \mathrm{N}\end{array}$

MDM4

$10 \cos 2$

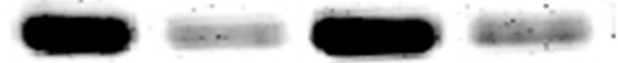

GAPDH
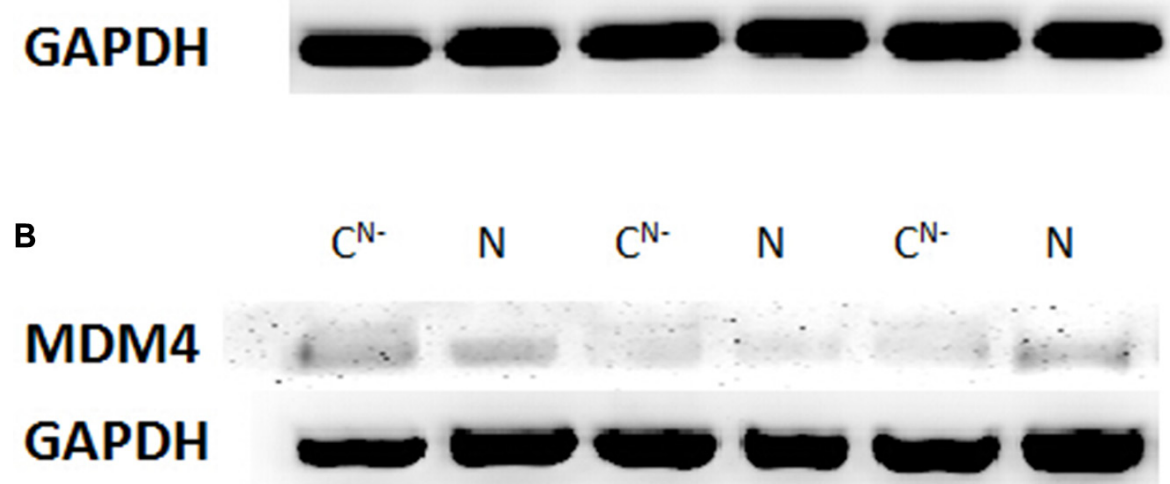

Figure 2: (A) The difference of MDM4 expression between GTAC tissues with positive lymph node metastasis and normal gastric tissues. (B) The difference of MDM4 expression between GTAC tissues with negative lymph node metastasis and normal gastric tissues.

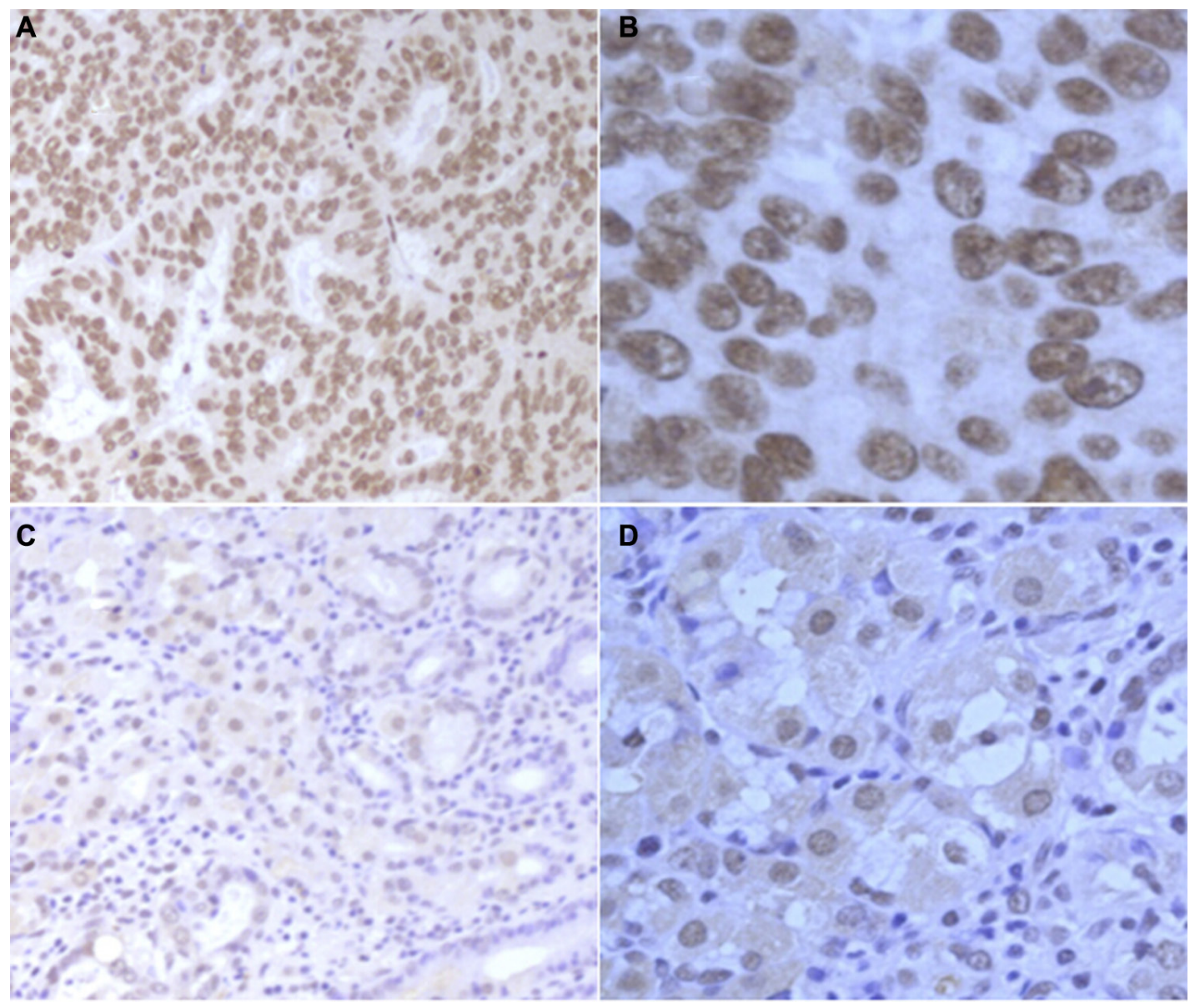

Figure 3: The protein expression of MDM4 in paraffin-embedded GTAC tissues and normal gastric tissues. (A) MDM4 high expression in GTAC tissue (100×). (B) MDM4 high expression in GTAC tissue (400×). (C) MDM4 low expression in normal gastric tissue $(100 \times)$. (D) MDM4 low expression in normal gastric tissue $(400 \times)$. 
Table 2: Univariate and multivariate analyses of the prognostic factors for TGAC patients

\begin{tabular}{|c|c|c|c|c|c|c|}
\hline Variables & HR & $\begin{array}{l}\text { Univariate } \\
95 \% \text { CI }\end{array}$ & $P$ & HR & $\begin{array}{c}\text { Multivariate } \\
\text { 95\% CI }\end{array}$ & $P$ \\
\hline \multicolumn{7}{|l|}{ Age(years) } \\
\hline$\geq 58$ vs $<58$ & 1.156 & $0.851-1.570$ & 0.353 & & & \\
\hline \multicolumn{7}{|l|}{ Gender } \\
\hline Female vs Male & 1.294 & $0.914-1.833$ & 0.147 & & & \\
\hline \multicolumn{7}{|l|}{ Tumour size (cm) } \\
\hline$>5$ vs $\leq 5$ & 2.269 & $1.661-3.100$ & 0.000 & 1.307 & $0.931-1.835$ & 0.123 \\
\hline \multicolumn{7}{|l|}{ Borrmann type } \\
\hline III-IV vs 0-III & 2.810 & $1.870-4.223$ & 0.000 & 1.719 & $1.119-2.640$ & 0.013 \\
\hline \multicolumn{7}{|l|}{ Depth of invasion } \\
\hline T3-4 vs T1-2 & 5.507 & $3.329-9.108$ & 0.000 & 2.810 & $1.551-5.092$ & 0.001 \\
\hline \multicolumn{7}{|l|}{ Lymph node metastasis } \\
\hline $\mathbf{N}+\mathbf{v s} \mathbf{N}-$ & 4.407 & $2.990-6.494$ & 0.000 & 3.256 & $1.913-5.541$ & 0.000 \\
\hline \multicolumn{7}{|l|}{ Pathological stage } \\
\hline III vs I/II & 3.567 & $2.593-4.906$ & 0.000 & 0.927 & $0.593-1.449$ & 0.740 \\
\hline \multicolumn{7}{|l|}{ Differentiation status } \\
\hline $\begin{array}{l}\text { Lack of differentiation } \\
\text { vs Differentiation }\end{array}$ & 1.829 & $1.224-2.732$ & 0.003 & 0.901 & $0.589-1.379$ & 0.633 \\
\hline \multicolumn{7}{|l|}{$\begin{array}{l}\text { Preoperative serum } \\
\text { CEA }\end{array}$} \\
\hline High vs Normal & 1.135 & $0.787-1.637$ & 0.498 & & & \\
\hline \multicolumn{7}{|l|}{$\begin{array}{l}\text { Preoperative serum } \\
\text { CA19-9 }\end{array}$} \\
\hline $\begin{array}{l}\text { High vs Normal } \\
\text { MDM4 }\end{array}$ & 2.691 & $1.856-3.902$ & 0.000 & 1.796 & $1.208-2.671$ & 0.004 \\
\hline Positive vs Negative & 1.943 & $1.430-2.641$ & 0.000 & 1.132 & $0.804-1.594$ & 0.476 \\
\hline
\end{tabular}

of overall prognosis relied on whether high MDM4 could lead to LNM. However, these findings need to be confirmed by a larger study.

\section{MATERIALS AND METHODS}

\section{Patient and tissue specimens}

Thirty pairs of fresh GTAC and corresponding normal mucosa tissue samples (more than $5 \mathrm{~cm}$ away from the GTAC edge) were obtained from patients between January 2015 and June 2015. And those samples were used for the Western blot analysis and the qRT-PCR analysis. A total of 336 paraffin-embedded tissues diagnosed with GTAC at the Department of Gastroenterologic Surgery, Harbin Medical University Cancer Hospital between January 2010 and December 2010, were used in the immunohistochemistry (IHC) analysis. Thirty-three matched normal gastric tissues were used as control samples. The 336 patients comprised of 238 men and 98 women aged 24-81 years old (mean age is 57.6 years old). None of the patients received preoperative anticancer treatment, and no patient had synchronous distant metastasis. Various clinicopathological parameters (i.e., age, gender, tumor size, Borrmann type, differentiation status, depth of invasion, LNM, pathological stage, preoperative serum CEA, and preoperative serum CA19-9) were obtained from histopathology records. The GTAC stage was described according to the 2010 tumor node metastasis classification of malignant tumors by the American Joint Committee on Cancer. The patients were followed-up until death or the last follow-up date (31 December 2015). All patients underwent complete follow-up, which ranged from 3 to 71 months. The patients provided written informed consents. An ethical approval was obtained from the Ethical Committee of Harbin Medical University Cancer Hospital.

\section{RNA extraction and $q$ RT-PCR}

Total RNAs were extracted from 30 pairs of fresh GTAC and adjacent normal gastric tissues by using E.Z.N.A. ${ }^{\circledR}$ Total RNA Kit (Omega Biotek Store, USA). The qualified total RNAs were reversely transcribed into the 
first-strand cDNAs by using the PrimeScript ${ }^{\circledR}$ RT Reagent Kit (Takara). The forward primer for the MDM4 gene was 5'-CTAAGTCCTTAAGTGATGATACCGATGT-3', and the reverse primer was $5^{\prime}$-AACTTTGAACAAT CTGAATACCAATCC-3'. The forward primer for the GAPDH gene was 5'-GGACCTGACCTGCCGTCTAG3 'the, and the reverse primer was 5'-GAGGAGTGGGT
GTCGCTGTT-3'. The qRT-PCR was conducted using an ABI 7500 RT-PCR amplifier (Applied Biosystems, USA) to determine the expression pattern of MDM4 mRNA in each GTAC sample and paired adjacent normal gastric tissue. The qRT-PCR was then performed using the SYBR ${ }^{\circledR}$ Premix Ex Taq ${ }^{\mathrm{TM}}$ II Kit (Takara) in a total volume of $20 \mu \mathrm{l}$. GAPDH was used as the reference gene.

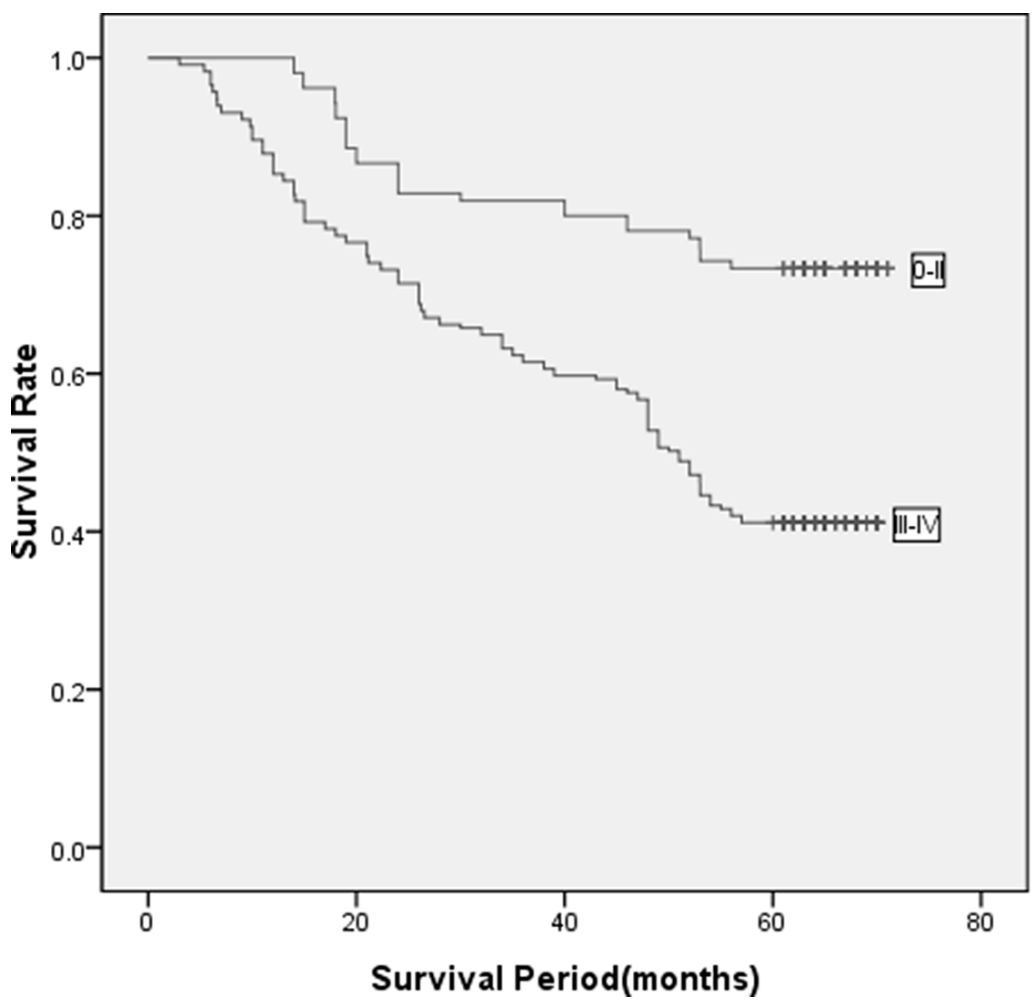

$$
\begin{aligned}
& \text { Borrmann type } \\
& -70-\| I \\
& -\neg \| I-I V \\
& +0-\| l-c e n s o r e d \\
& + \text { III-IV-censored }
\end{aligned}
$$

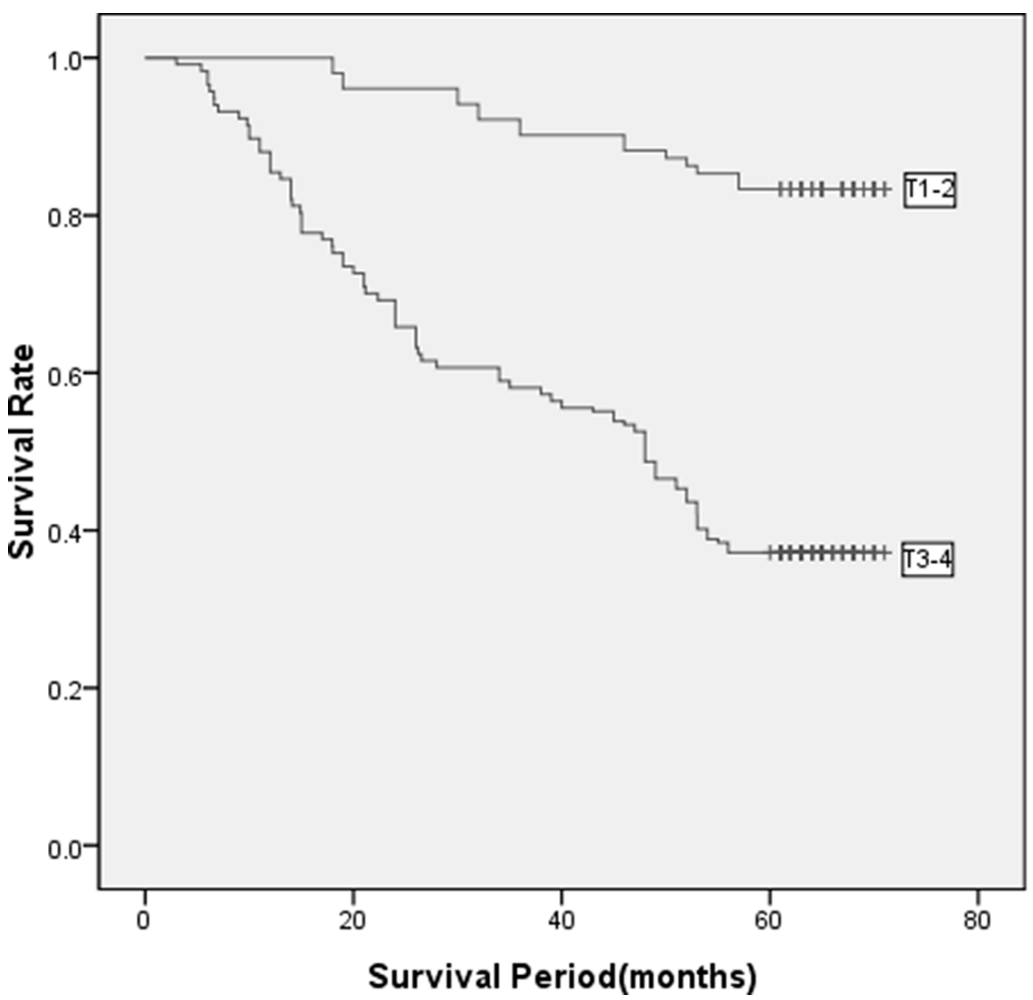

Depth of Invasion

$-\neg T 1-2$

$\neg T 3-4$

+T1-2-censored

+ T3-4-censored 

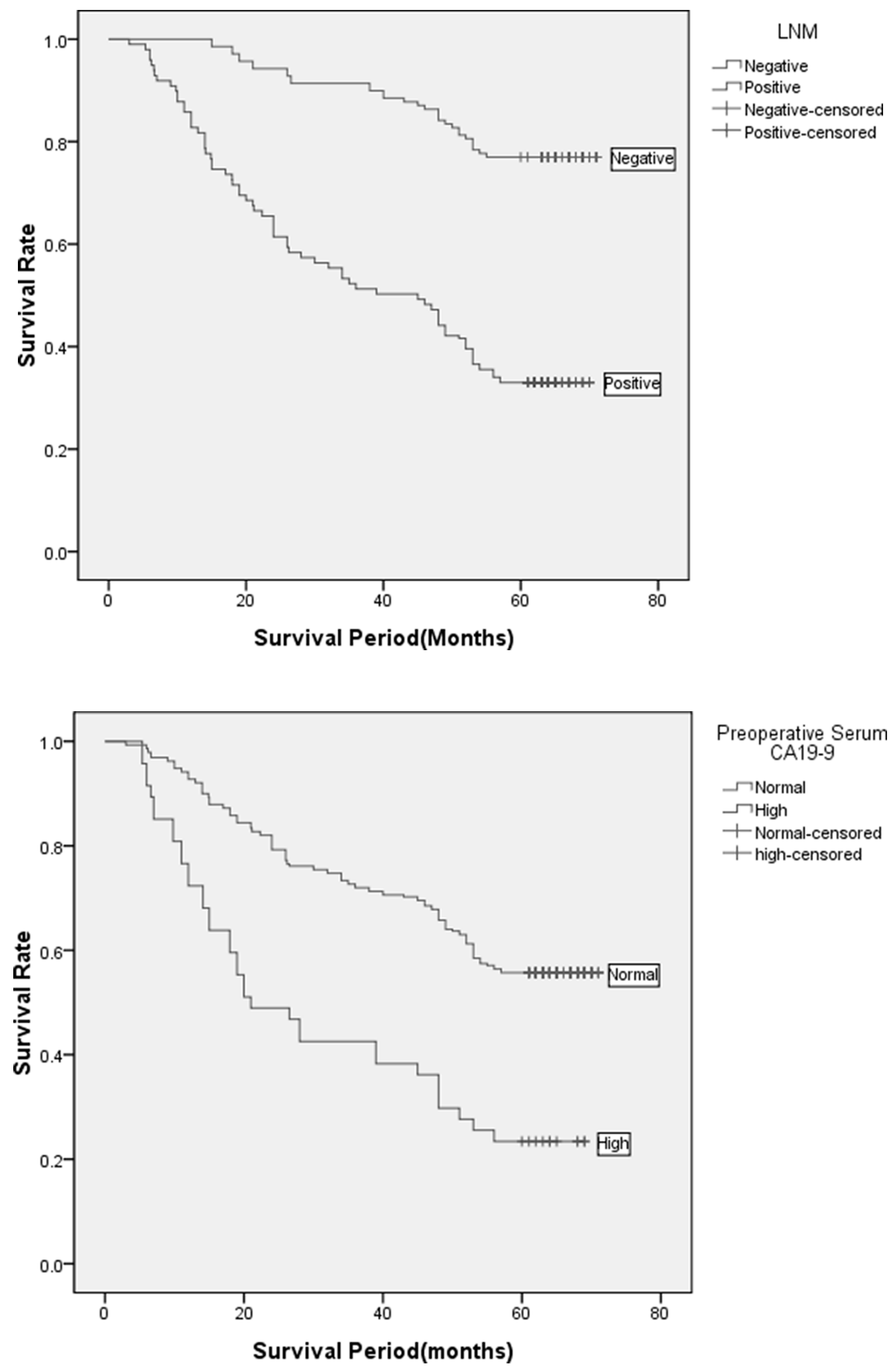

Figure 4: (A) Kaplan-Meier analysis of OS among GTAC patients based on Borrmann type. (B) Kaplan-Meier analysis of OS among GTAC patients based on Depth of Invasion. (C) Kaplan-Meier analysis of OS among GTAC patients based on the condition of lymph node metastasis. (D) Kaplan-Meier analysis of OS among GTAC patients based on the CA19-9 level of pre-operation. 
The relative gene expression levels were represented as $\Delta \mathrm{Ct}=\mathrm{Ct}$ (gene) $-\mathrm{Ct}$ (reference). The fold change of gene expression was calculated using the $2^{-\Delta \Delta \mathrm{Ct}}$ method. The experiments were repeated in triplicate.

\section{Western blot analysis}

Total protein was isolated from 30 pairs of fresh GTAC and adjacent normal gastric tissues. An equal amount of protein from the tissues was separated through sodium dodecyl sulfate-polyacrylamide gel electrophoresis and transferred to a polyvinylidene membrane. The membranes were blocked with 5\% fat-free milk in Trisbuffered saline containing $0.1 \%$ Tween-20 (TBST) for $1 \mathrm{~h}$ at room temperature. The membranes were then incubated overnight at $4{ }^{\circ} \mathrm{C}$ with anti-MDM4 (1:1000, Abgent, USA) antibody or anti-GAPDH $(1: 1000, \mathrm{ZsBio}, \mathrm{China})$. The membranes were washed three times with TBST buffer for $10 \mathrm{~min}$ and then incubated with the secondary antibody, anti-rabbit IgG (1:1000, ZsBio, China) or anti-mouse IgG $(1: 1000, \mathrm{ZsBio}, \mathrm{China})$ at room temperature for $1 \mathrm{~h}$. The membranes were subsequently washed with TBST three times. The immunoreactive bands were visualized using the ECL plus Western blot detection kit.

\section{IHC analysis}

MDM4 expression in 336 GTAC and 33 normal gastric tissues was examined using IHC. The samples were fixed in formalin, embedded in paraffin, cut into $4 \mu \mathrm{m}$-thick sections, and mounted on silane-coated slides. Antigen was retrieved by immersing the samples in EDTA ( $\mathrm{pH}$ 8.0) at high pressures for $2.5 \mathrm{~min}$. The sections were then incubated in a humidified chamber at $4^{\circ} \mathrm{C}$ overnight with the primary antibody, mouse anti-MDM4 (diluted 1:250, Abcam, USA). The sections were incubated with biotinylated IgG secondary antibody (ZsBio, China) after washing three times in phosphate-buffered saline (PBS). The color was developed with 3,3'-diaminobenzidine DAB solution. The specificity of immunostaining was confirmed by obtaining negative controls through the replacement of the primary antibody with PBS. MDM4 expression was scored by multiplying the percentage of positive tumor cells and staining intensity. The percentage of the positive cells was initially scored into 0 (0\%), $1(1 \%-25 \%), 2(25 \%-50 \%), 3(50 \%-75 \%)$, and 4 (75\%-100\%). Thereafter, staining intensity was scored as follows: 0 (negative), 1 (weakly positive), 2 (moderately positive), and 3 (strongly positive). The immunostaining score, also known as staining index (SI), was calculated for each case by multiplying the percentage of positive cells with the staining intensity score, the resulting score is widely used in many malignant tumor studies [31,32]. The immunohistochemistry scoring procedure was carried out to duplicate by two experienced pathologists to evaluate immunohistochemistry. The experienced pathologists did not know the clinicopathological information or the corresponding H\&E slide. In the cases of scores with discrepancies, the results of immunohistochemistry were evaluated by additional pathologists until the consensus was reached. The obtained value ranged from 0 to 12 . An optimal cut-off value was identified as follows: an SI score of six or higher was used to define tumors with high MDM4 protein expression level, and an SI score of less than six was used to indicate low expression levels.

\section{Statistical analysis}

The statistical analysis was performed using the SPSS statistical software package (standard version 13.0; SPSS, Chicago, IL, USA). Student's $t$-test was used to analyze qRT-PCR data. The correlation between MDM4 expression and clinicopathological characteristics was analyzed using Pearson chi-squared test. The type of Cox regression model chosen was enter method. The survival curves were plotted using Kaplan-Meier method and then compared using the log-rank test.

\section{ACKNOWLEDGMENTS AND FUNDING}

This study was supported a grant supported by the Harbin Medical University Cancer Hospital. The authors also deeply appreciate the external assistance from Dr. Fanling Meng and Yuyan Ma.

We declare that we have no financial and personal relationships with other people or organizations that can inappropriately influence our work, there is no professional or other personal interest of any nature or kind in any product, service and/or company that could be construed as influencing the position presented in, or the review of, the manuscript entitled.

\section{CONFLICTS OF INTEREST}

None.

\section{REFERENCES}

1. Siegel R, Ma J, Zou Z, Jemal A. Cancer statistics, 2014. CA Cancer J Clin. 2014; 64:9-29. doi: 10.3322/caac.21208.

2. Ferlay J, Shin HR, Bray F, Forman D, Mathers C, Parkin DM. Estimates of worldwide burden of cancer in 2008: GLOBOCAN 2008. Int J Cancer. 2010; 127:2893-917. doi: 10.1002/ijc.25516.

3. Lee SR, Kim HO, Son BH, Shin JH, Yoo CH. Prognostic significance of the metastatic lymph node ratio in patients with gastric cancer. World J Surg. 2012; 36:1096-101. doi: 10.1007/s00268-012-1520-5.

4. Deng J, Zhang R, Pan Y, Wang B, Wu L, Hao X, Liang H. $\mathrm{N}$ stages of the seventh edition of TNM Classification are the most intensive variables for predictions of the overall 
survival of gastric cancer patients who underwent limited lymphadenectomy. Tumour Biol. 2014; 35:3269-81. doi: 10.1007/s13277-013-1428-1.

5. Siewert JR, Bottcher K, Stein HJ, Roder JD. Relevant prognostic factors in gastric cancer: ten-year results of the German Gastric Cancer Study. Ann Surg. 1998; 228:449-61. doi:

6. Kwee RM, Kwee TC. Imaging in assessing lymph node status in gastric cancer. Gastric Cancer. 2009; 12:6-22. doi: 10.1007/s10120-008-0492-5.

7. Fukuya T, Honda H, Hayashi T, Kaneko K, Tateshi Y, Ro T, Maehara Y, Tanaka M, Tsuneyoshi M, Masuda K. Lymphnode metastases: efficacy for detection with helical CT in patients with gastric cancer. Radiology. 1995; 197:705-11. doi: 10.1148/radiology.197.3.7480743.

8. Tan BX, Khoo KH, Lim TM, Lane DP. High Mdm4 levels suppress p53 activity and enhance its half-life in acute myeloid leukaemia. Oncotarget. 2014; 5:933-43. doi: 10.18632/oncotarget.1559.

9. Zhou L, Zhang X, Li Z, Zhou C, Li M, Tang X, Lu C, Li H, Yuan Q, Yang M. Association of a genetic variation in a miR-191 binding site in MDM4 with risk of esophageal squamous cell carcinoma. PLoS One. 2013; 8:e64331. doi: 10.1371/journal.pone.0064331.

10. Shvarts A, Steegenga WT, Riteco N, van Laar T, Dekker P, Bazuine M, van Ham RC, van der Houven van Oordt W, Hateboer G, van der Eb AJ, Jochemsen AG. MDMX: a novel p53-binding protein with some functional properties of MDM2. EMBO J. 1996; 15:5349-57.

11. Cancer Genome Atlas Research N. Comprehensive molecular characterization of gastric adenocarcinoma. Nature. 2014; 513:202-9. doi: 10.1038/nature13480.

12. Cui J, Li D, Zhang W, Shen L, Xu X. Bioinformatics analyses combined microarray identify the deregulated microRNAs in oral cancer. Oncol Lett. 2014; 8:218-22. doi: 10.3892/ol.2014.2070.

13. Zhang XF, Huang CM, Lu HS, Wu XY, Wang C, Guang GX, Zhang JZ, Zheng CH. Surgical treatment and prognosis of gastric cancer in 2,613 patients. World J Gastroenterol. 2004; 10:3405-8.

14. Monig SP, Zirbes TK, Schroder W, Baldus SE, Lindemann DG, Dienes HP, Holscher AH. Staging of gastric cancer: correlation of lymph node size and metastatic infiltration. AJR Am J Roentgenol. 1999; 173:365-7. doi: 10.2214/ajr.173.2.10430138.

15. Takatsu Y, Hiki N, Nunobe S, Ohashi M, Honda M, Yamaguchi T, Nakajima T, Sano T. Clinicopathological features of gastric cancer in young patients. Gastric Cancer. 2015. doi: 10.1007/s10120-015-0484-1.

16. Gurzu S, Kadar Z, Sugimura H, Bara T, Bara T, Jr., Halmaciu I, Jung I. Gastric cancer in young vs old Romanian patients: immunoprofile with emphasis on maspin and mena protein reactivity. APMIS. 2015; 123:223-33. doi: 10.1111/apm.12347.

17. Zheng Z, Zhang Y, Zhang L, Li Z, Wu X, Liu Y, Bu Z, Ji J. A nomogram for predicting the likelihood of lymph node metastasis in early gastric patients. BMC Cancer. 2015; 16:92. doi: 10.1186/s12885-016-2132-5.

18. Zhao BW, Chen YM, Jiang SS, Chen YB, Zhou ZW, Li YF. Lymph Node Metastasis, a Unique Independent Prognostic Factor in Early Gastric Cancer. PLoS One. 2015; 10:e0129531. doi: 10.1371/journal.pone.0129531.

19. Song YX, Huang XZ, Gao P, Sun JX, Chen XW, Yang YC, Zhang C, Liu HP, Wang HC, Wang ZN. Clinicopathologic and Prognostic Value of Serum Carbohydrate Antigen 19-9 in Gastric Cancer: A Meta-Analysis. Dis Markers. 2015; 2015:549843. doi: 10.1155/2015/549843.

20. Gaspar MJ, Arribas I, Coca MC, Diez-Alonso M. Prognostic value of carcinoembryonic antigen, CA 19-9 and CA 72-4 in gastric carcinoma. Tumour Biol. 2001; 22:318-22. doi: 50633.

21. Ach T, Schwarz-Furlan S, Ach S, Agaimy A, Gerken M, Rohrmeier C, Zenk J, Iro H, Brockhoff G, Ettl T. Genomic aberrations of MDM2, MDM4, FGFR1 and FGFR3 are associated with poor outcome in patients with salivary gland cancer. J Oral Pathol Med. 2015. doi: 10.1111/jop.12394.

22. Li C, Oh SJ, Kim S, Hyung WJ, Yan M, Zhu ZG, Noh SH. Macroscopic Borrmann type as a simple prognostic indicator in patients with advanced gastric cancer. Oncology. 2009; 77:197-204. doi: 10.1159/000236018.

23. Luo Y, Gao P, Song Y, Sun J, Huang X, Zhao J, Ma B, Li Y, Wang Z. Clinicopathologic characteristics and prognosis of Borrmann type IV gastric cancer: a meta-analysis. World J Surg Oncol. 2016; 14:49. doi: 10.1186/s12957-016-0805-9.

24. Yamashita K, Hosoda K, Katada N, Moriya H, Mieno H, Higuchi K, Sasaki T, Katada C, Sakuramoto S, Tanabe S, Koizumi W, Kikuchi S, Watanabe M. Survival outcome of Borrmann type IV gastric cancer potentially improved by multimodality treatment. Anticancer Res. 2015; 35:897906. doi:

25. Ru GQ, Wang HJ, Xu WJ, Zhao ZS. Upregulation of Twist in gastric carcinoma associated with tumor invasion and poor prognosis. Pathol Oncol Res. 2011; 17:341-7. doi: 10.1007/s12253-010-9332-0.

26. Song Y, Zhao F, Wang Z, Liu Z, Chiang Y, Xu Y, Gao P, $\mathrm{Xu} \mathrm{H}$. Inverse association between miR-194 expression and tumor invasion in gastric cancer. Ann Surg Oncol. 2012; 19 Suppl 3:S509-17. doi: 10.1245/s10434-011-1999-2.

27. Bu Z, Zheng Z, Li Z, Zhang L, Wu A, Wu X, Sun Y, Ji J. Lymphatic vascular invasion is an independent correlated factor for lymph node metastasis and the prognosis of resectable T2 gastric cancer patients. Tumour Biol. 2013; 34:1005-12. doi: 10.1007/s13277-012-0637-3.

28. Gao Y, Xu D, Yu G, Liang J. Overexpression of metabolic markers HK1 and PKM2 contributes to lymphatic metastasis and adverse prognosis in Chinese gastric cancer. Int J Clin Exp Pathol. 2015; 8:9264-71.

29. Yajima H, Omura N, Matai K, Mitsumori N, Yoshida K, Yanaga K. Clinicopathological features of CA19-9-producing gastric cancer. Hepatogastroenterology. 2014; 61:221-5. 
30. Kim JH, Jun KH, Jung H, Park IS, Chin HM. Prognostic Value of Preoperative Serum Levels of Five Tumor Markers (Carcinoembryonic Antigen, CA19-9, Alphafetoprotein, CA72-4, and CA125) in Gastric Cancer. Hepatogastroenterology. 2014; 61:863-9.

31. Conner JR, Hirsch MS, Jo VY. HNF1beta and S100A1 are useful biomarkers for distinguishing renal oncocytoma and chromophobe renal cell carcinoma in FNA and core needle biopsies. Cancer Cytopathol. 2015; 123:298-305. doi: 10.1002/cncy.21530.
32. Cimino-Mathews A, Subhawong AP, Elwood H, Warzecha HN, Sharma R, Park BH, Taube JM, Illei PB, Argani P. Neural crest transcription factor Sox10 is preferentially expressed in triple-negative and metaplastic breast carcinomas. Hum Pathol. 2013; 44:959-65. doi: 10.1016/j.humpath.2012.09.005. 